\title{
The interaction between road network and natural landscape type
}

\author{
N. Eliou ${ }^{1} \&$ F. Kehagia ${ }^{2}$ \\ ${ }^{1}$ University of Thessaly, Volos, Greece \\ ${ }^{2}$ Department of Civil Engineering of AUTh, Thessaloniki
}

\begin{abstract}
The construction of new road infrastructure can impact on landform in a number of ways. The type of natural landscape and the terrain or topographical features of the land determines where roads can go and therefore strongly affect road-network structure and pattern.

Several ecological impacts of road system occur at much greater levels than the proportion or road surface in the landscape. The main concept in road design is the understanding and the integration of the road network in a broader landscape in order to implement the basic rules of sustainable development. Decisions on design will require environmental constraints to be balanced against cost, but ultimately will be dependent upon engineering feasibility and safety considerations.

In the present paper, the interaction and the influence of the properties of different type of landscape such as topography and land use to the road network are examined.
\end{abstract}

Keywords: landscape type, road design, ecology.

\section{Introduction}

The road construction sector has to take a diverse and often complex range of factors into account. Environmental issues are an increasingly import part of the design and planning stage, with a focus on minimising or mitigating the impact of each new road link. The basic benefits of the mobility of people and goods, namely the effective and efficient transportation from one location to another and the provision of access to goods, resources and services, are unquestionable. However, the implementation of the "Sustainable Development" has introduced 
new ideas and directions in designing projects. Sustainability has a time horizon that extends over human generations and focuses on conservation of natural resources while providing for basic social and economic conditions. The constraints affecting new projects were not only technical and economic but perceived threats to the quality of the environment have led to an increasing awareness about a project to be in harmony with the environment. According to this new philosophy, engineers and contractors of a new road project, have to make sure that the economic, social and environmental needs, from the new project, can be met efficiently and in an integrated manner.

The construction of new road infrastructure can impact on landform in a number of ways. The type of the natural landscape, the terrain or topographical features of the land determines where roads can go and therefore strongly affect road-network structure and pattern. Several ecological impacts of road system occur at much greater levels than the proportion or road surface in the landscape. The main concept in road design is the understanding and the integration of the road network in a broader landscape in order to be implemented the basic rules of sustainable development. In the present paper, the interaction and the influence of the properties of different type of landscape such as topography and land use to the road network are examined.

\section{Landscape and road}

The landscape concept, by definition, implies the integration of economic, environmental and social-cultural qualities in physical settings. It is about natural features, about the farmed and wooden landscape or countryside, and about the patterns of human settlements and the relationship between all these things. Where human activities and land uses are more independent of the distribution of natural resources, boundaries of landscapes tend to be less distinct.

Road construction is strongly dependent on topography, soil, land cover but also human settlements. An intimate relationship between roads and land use grows because where roads are built new settlements, farms, fields or other human facilities are likely to follow. For new designed projects, landscape considerations are examined by the engineers with the help of specialists (environmental professionals and landscape architects) in order to determine the sites along the road, to highlight prevailing characteristics, identify the openings provided by the route and measure their impact on the existing landscape patterns. The decision of the altitude of the vertical alignment or the different cross sections as the integration of cuttings, embankments, viaducts or bridges will obviously not have the same effects on the landscape [6].

Road construction affects the immediate environment due to the need to clear, level, fill and cut. Construction work changes soil density, landscape relief, surface and ground water flows. This, in turn, can affect ecosystems, vegetation and fauna in the wider landscape. The magnitude of the reduction of the environmental quality of the areas adjacent the road is not clear measurable. It is depended on different factors as: 
- $\quad$ road and traffic characteristics

- $\quad$ landscape topography and hydrology

- wind and vegetation

- slope

- $\quad$ sensitivity of the different species

A different way of thinking can provide possibilities for achieving a greater degree of ecological sustainability in any further development. The new way will need to be inspired by the essential characteristics of living systems and it is important that the assumptions upon which the road infrastructure is carried out are made more combined with them. Taking the living systems into account could create a system of infrastructure that is characterised by a greater degree of comprehensiveness, achieves higher aesthetic values and has a higher quality for society.

It was about 1976, that Thayer emphasised the need to make ecology more visible and he spoke about the "visual ecology", a new sort of aesthetics about the value of nature and the possible relationship between culture, nature and design. In 2003, Forman, developed the idea of "road ecology" as an integral component of sustainable development and sustainable transportation [3].

The landscape integration integrates the highway with the character of the surrounding landscape by maintaining the matrix of local vegetation patterns, blending with local landform and softening views of the highway, its infrastructure and its traffic. The land is composed by patches, corridors, and a background matrix. Each has simple characteristics. The heterogeneity provided by patches and corridors in an area plays a key role in sustainability [2]. It is important to maintain a few large patches of natural vegetation or wide vegetation corridors along major water courses. Another key component is maintaining connectivity for movement of key species among the large patches. Establishing a new road infrastructure in a landscape is equivalent to adding a new ecosystem to the existing one. Roads can be defined as ecosystems because they occupy ecological space, have structure, support a specialised biota, exchange matter and energy with other ecosystems and experience temporal change [7].

According to this idea, evaluating the ecological effects of roads requires rigorous analysis and an understanding of the ecology of roads, that is, the interplay between all of the living components, the function of roads and the environmental factors that regulate processes along the road corridor [8].

\section{Built land and road}

Cities provide a great part of human activities. It is important to enhance the surrounding landscape and built elements of the road, to reflect the scale, character and materials of the local community through which the road passes. The need of living, working in or utilising areas within or adjacent to the road plays a key role in order to determine the design and materials used for the infrastructure as footways, cyclists road etc. The enhancement of amenity is also important for those using public transport or local facilities. 


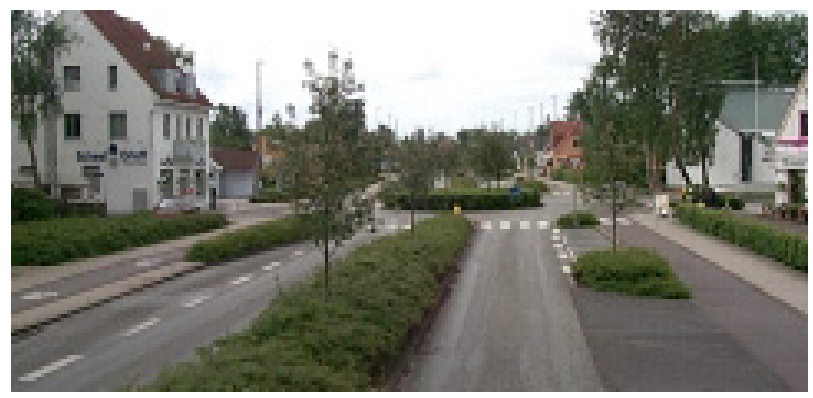

Figure 1: Enhancing the built environment.

Effective measures have to be designed and implemented to provide accessibility, public safety and upgrading of urban landscape. Most business areas exhibit a road density of about $40 \mathrm{~km} / \mathrm{km}^{2}$. Ecologically, city roads and traffic contaminate the surrounding environment with a variety of chemical pollutants and noise. Roads play a major role in aquatic pollution in city and settings. In earth terrain with natural vegetation, most precipitation water infiltrates into the ground. But when the ground is replaced of hard-surface cover as roads, buildings, parking areas etc., reduce runoff with many chemical pollutants carried. In the built areas fewer and smaller areas remain with natural vegetation. Furthermore, how roads are placed will have strong influence on hydrologic processes and aquatic ecology. Appropriative measures have to receive watercourses and groundwaters and to protect from unacceptable impacts from pollutants.

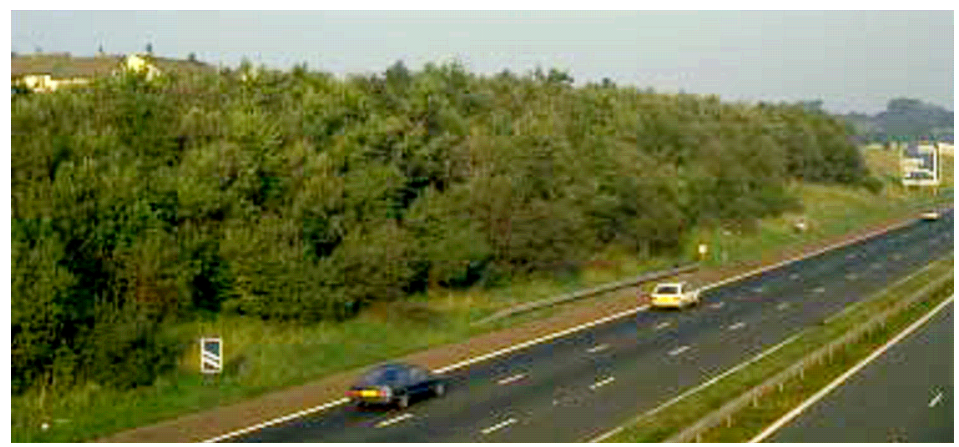

Figure 2: Visual screening.

At suburban areas, a combination of mounding and planting in areas of significant impact provides the optimum combination and enhances visual amenity. Mitigation against adverse visual impacts has as result of screening views of the highway and associated infrastructure from properties and public viewpoints, including rights of way and public open space (Figure 2). 


\section{Agriculture land and road}

An understanding of appropriate scale and landscape context is essential for good alignment and design. The physical presence of roads in the landscape creates new habitat edges, alters hydrological dynamics and disrupts natural processes and habitats. Infrastructure and traffic imposes barriers to most animals and the causes the death of millions of individual animals per year.

The arrangement of fields on slopes and relative to streams is critical to erosion. In agricultural land erosion and mineral nutrients are especially threatening to streams, wetlands and aquifers. Wetlands are especially sensitive to changes in hydrology as caused by road embankments. River corridors require specific design and effective construction methods and maintenance techniques (Figure 3). Alter flows can have major physical or chemical effects on aquatic ecosystems. Water runoff and sediment yield are the key physical processes whereby roads have an impact on streams and other aquatic systems. Especially, following a valley bottom can have a major impact on river and vegetation patterns along the valley bottom.

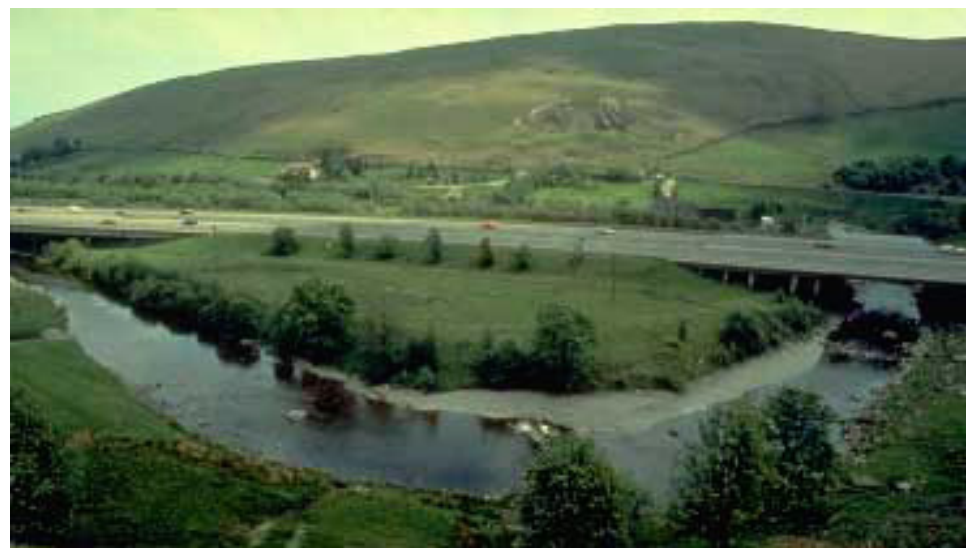

Figure 3: Rivers corridors and highway.

Special soil and vegetation techniques may be specified to achieve an interface with the adjacent land. Grading out of earthworks, cuttings and embankments, where it is appropriate, is a useful way of disposing surplus material and provides better integration with the surrounding landscape, because of returning the slope to agriculture [4].

\section{Forest land and road}

In forest land, topography strongly influences the locations of roads. It is important to find an alignment which least damages the existing landform and which minimises the scale of earthworks. Following the contours, in general, is good practice, because of the reduction of earthworks and minimising of disturbance. 


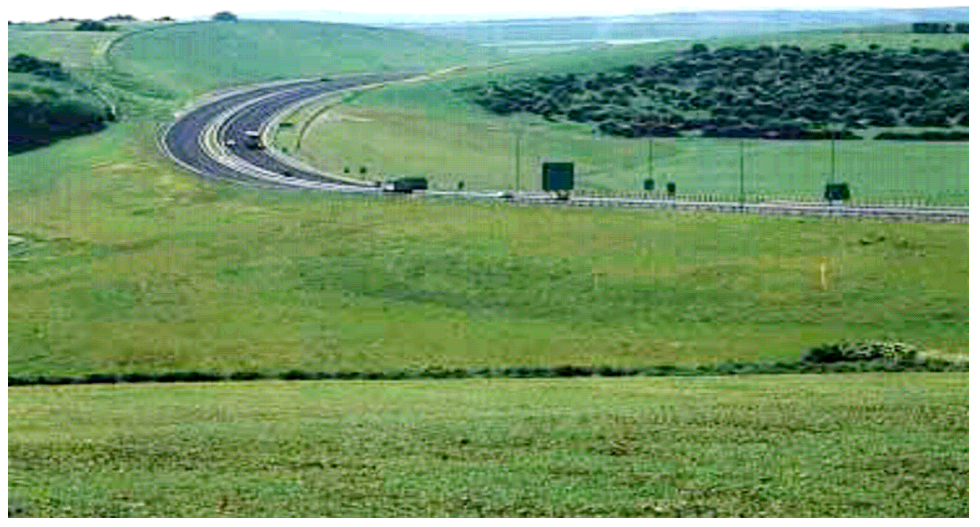

Figure 4: Grading out of earthworks.

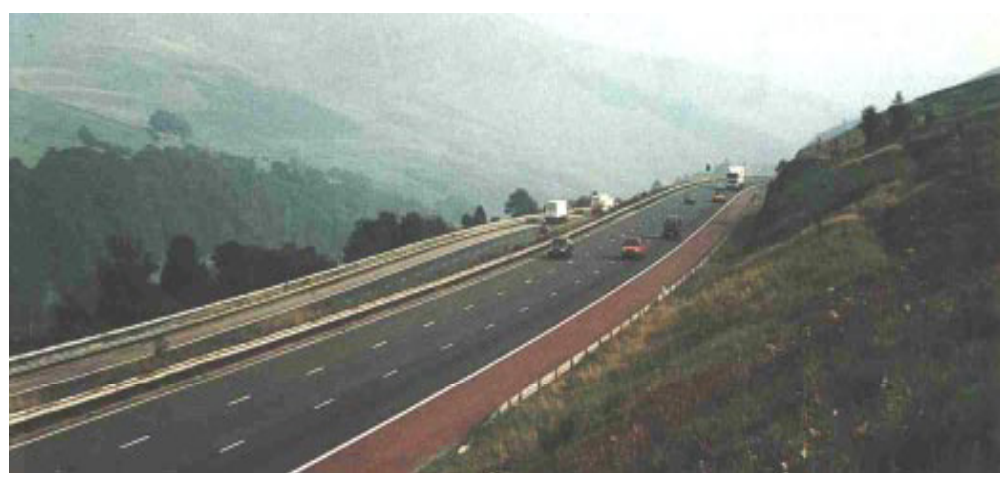

Figure 5: Integration with the texture of landscape is essential.

The disturbance in the environment from the construction of a new road is significant and it is depended on topography, climate, soil and land-use practices. Highways may consume more than 10 ha of land per kilometre road, due to the all area of associated features, such as right-of-way, embankments, slope cuttings. Infrastructure affects nature in both direct and indirect ways. Disturbance effects spread into the surrounding landscape and contribute far more to the overall loss and degradation of natural habitat than the road body itself. Barrier effects isolate habitats and make them inaccessible for wildlife. Edge effects on hydrology and microclimate and the pollution by toxins, nutrients and noise reduce the suitability of the remaining habitats. Where roads cut through forested habitats, microclimatic conditions are strongly altered. Increased wind and light intensity, reduced air humidity and temperature 
disfavour forest interior species. Effects on vegetation and fauna due to edge effects have been observed up to several meters away from the road. In steep mountain slope areas, roads affect aquatic ecosystems mainly by altering flows of water and sediment.

\section{Conclusions}

Sustainable development and the meaning of nature have led to a need to a sustainable equilibrium between improving accessibility and improving the quality of life. Accessibility primarily involves maintaining and making better use of the existing infrastructure.

The basic measures to minimise the negative impacts of landscape due to road infrastructure are:

a) The avoidance of negative impact: is relevant when selecting the route for new or improved road in order to prevent an area of great ecological significance.

b) The mitigation: implies attempts to reduce the negative impacts if they appear to be unavoidable. This is done with specific projects.

c) Where avoidance is impossible and mitigation is not enough, one can opt for compensation. This involves making good the loss to nature caused by constructing or improving a highway by providing equivalent nature somewhere else, preferable in the same general area.

d) Optimisation involves harmonising the mitigating measures and the laying out and management of the highway verges as much as possible.

However, to understand the complex environmental impact of road infrastructure and amend it in an ecologically sound and sustainable manner, a holistic landscape approach is needed taking into account both cultural and natural aspects in the landscape [8].

\section{References}

[1] Cuperus R., Guidelines for ecological compensation associated with highways, Biological Conservation 90 (1999), pp 41-51

[2] Forman R., Land Mosaics, The ecology of landscapes and region, Cambridge University Press, 1995

[3] Forman R., Road Ecology. Science and Solutions, 2003, Island Press

[4] Georgi J., Zafeiriadis K., Landscape restoration strategy and the reduction of environmental impact to the road constructions in Greek landscapes, Protection and restoration of the environment VI, 2002, pp

[5] H.D. van Bohemen, Habitat fragmentation, infrastructure and ecological engineering, Ecological Engineering 11 (1998), pp 199-207

[6] Kehagia F., Eliou N., Integration of road design into the surrounding landscape, WSEAS Transactions on Environment and Development, Issue 1, Vol. 2, pp 65-69 
868 Sustainable Development and Planning III

[7] Lugo A., Gucinski H., Function, effects and management of forest roads, Forest Ecology and Management 133 (2000), pp 249-262

[8] Seiler A., Ecological Effects of Roads. A review, Department of Conservation Biology, Uppsala 2001 